\title{
LOCAL GROWTH ENVELOPES OF SPACES OF GENERALIZED SMOOTHNESS: THE CRITICAL CASE
}

\author{
António M. CAetano And Susana D. Moura
}

Abstract. The concept of local growth envelope of a quasi-normed function space is applied to the spaces of Besov and Triebel-Lizorkin type of generalized smoothness $(s, \Psi)$ in the critical case $s=n / p$, where $s$ stands for the main smoothness, $\Psi$ is a perturbation and $p$ stands for integrability. The expression obtained for the behaviour of the local growth envelope functions (which, as expected, depends on $\Psi$ ) shows the ability to be generalized to a form unifying both critical $(s=n / p)$ and subcritical $(s<n / p)$ cases.

Mathematics subject classification (2000): 46E35.

Key words and phrases: growth, envelope, Besov, Triebel-Lizorkin, generalized, smoothness.

\section{REFERENCES}

[1] C. BENNETT AND R. Sharpley, Interpolation of operators, Academic Press, Boston, 1988.

[2] A. M. CAETANO AND S. D. MourA, Local growth envelopes of spaces of generalized smoothness: the sub-critical case, to appear in Math. Nachr.

[3] D. E. Edmunds And H. TRIEBEL, Spectral theory for isotropic fractal drums, C. R. Acad. Sci. Paris 326(I) (1998), 1269-1274.

[4] Eigenfrequencies of isotropic fractal drums, Oper. Theory Adv. Appl. 110 (1999), 81-102.

[5] W. FARKAS AND H.-G. LEOPOLD, Characterisations of function spaces of generalised smoothness, preprint Math/Inf/23/01, Friedrich-Schiller-Univ. Jena, 2001.

[6] G. HARdy, J. E. LitTlewOOd AND G. Pólya, Inequalities, reprinted second ed., Cambridge U. P., 1994.

[7] D. D. HAROSKE, Envelopes in function spaces - a first approach, preprint Math/Inf/16/01, Univ. Jena, Germany, 2001.

[8] G. A. Kalyabin, Criteria of the multiplication property and the embedding in $C$ of spaces of Besov-Lizorkin-Triebel type, Mat. Zametki 30 (1981), 517-526, (Russian).

[9] H.-G. LEOPOLD, Embeddings and entropy numbers in Besov spaces of generalized smoothness, "Function Spaces: The fifth conference", Lecture notes in pure and applied math. 213, (ed. H. Hudzig and L. Skrzypczak) Marcel Dekker, 2000, pp. 323-336.

[10] S. Moura, Function spaces of generalised smoothness, Dissertationes Math. 398 (2001), 88 pp.

[11] Function spaces of generalised smoothness, entropy numbers, applications, Ph.D. thesis, University of Coimbra, 2001.

[12] B. OpIC AND W. TREBELS, Sharp embeddings of Bessel potential spaces with logarithmic smoothness, Math. Proc. Camb. Phil. Soc. 134 (2003), 347-384.

[13] W. SicKEL AND H. TRIEBEL, Hölder inequalitites and sharp embeddings in function spaces of $B_{p q}^{s}$ and $F_{p q}^{s}$ type, Z. Anal. Anwendungen 14 (1995), no. 1, 105-140.

[14] H. TRIEBEL, Spaces of Besov-Hardy-Sobolev type, Teubner, Leipzig, 1978.

[15] Theory of function spaces, Birkhäuser, Basel, 1983.

[16] Fractals and spectra, Birkhäuser, Basel, 1997.

[17] , The structure of functions, Birkhäuser, Basel, 2001. 